\title{
Ezafe: A Problematic Invisible Phoneme for Iranian EFL Learners
}

\author{
Mohammad Abdollahi Guilani, PhD, (Corresponding author) \\ School of Language Studies and Linguistics, Faculty of Social Science and Humanities \\ Universiti Kebangsaan Malasyia, Malaysia \\ E-mail: abdollahi20@gmail.com \\ Mohamad Subakir Mohd Yasin, $\mathrm{PhD}$ \\ School of Language Studies and Linguistics, Faculty of Social Science and Humanities \\ Universiti Kebangsaan Malasyia, Malaysia \\ E-mail: subakir@ukm.my \\ Tan Kim Hua, Assoc Prof Dr. \\ School of Language Studies and Linguistics, Faculty of Social Science and Humanities \\ Universiti Kebangsaan Malasyia, Malaysia \\ E-mail: kimmy@ukm.my
}

Received: August 16, 2011

Accepted: October 9, $2011 \quad$ Published: February 1, 2012

doi:10.5539/ijel.v2n1p188

URL: http://dx.doi.org/10.5539/ijel.v2n1p188

\begin{abstract}
Ezafe, as an indispensable phoneme of the Persian language, does not exist visually, but its presence is extremely effective. It is an enclitic usually realized by /-e / or /-ye/ and mostly suffixed to nouns. The presence of the Ezafe is a must when a noun is modified. Ezafe can show different relations like possession and addition. It assumes such roles as definite and indefinite articles, the verb "be", and stands for certain English prepositions. The presence of the Ezafe in Persian can lead to fluency and correct comprehension. No transitive verbs followed by objects can do without the Ezafe enclitic. This paper classifies different phonological and syntactic uses of the Ezafe, discussing its application against the English syntactic positions of words. The paper exhibits the probability of committing mistakes by the Iranian English learners when the Ezafe enclitic is included in or excluded from their foreign language communication.
\end{abstract}

Keywords: Enclitic, Modifier, Phoneme, Preposition, Syntax

\section{Introduction}

Modern Persian, the sole official language in Iran, belongs to the Southwest branch of the Iranian branch of Indo-European. A normal sentence usually starts with a subject, followed by an object and ended in a verb. Adjectives and nouns which describe other nouns are usually postmodifiers. However, demonstratives and numerals precede the head. In Modern Persian, there is one accusative case marker, "RA", that is placed after the object but other case relations are expressed through prepositions, placed in front of the nouns being described. The term 'Ezafe' is adopted from Arabic grammar, where it means 'addition, supplement' (Haig: Online). The Ezafe is an unstressed enclitic phoneme which follows a noun, pronoun, adjective and even some prepositions provided that there is a modifier following them. The Ezafe is, in fact, a verbal /-e / vowel attached to a word

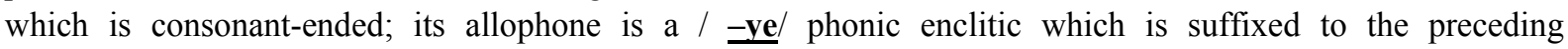
vowel-ended word. However, in standard Persian orthography (based on the Arabic script) it does not appear at all, except for pedagogical or stylish cases. Thus, in the written language, the presence of an Ezafe can usually be inferred only from the context when the adjacent words are read aloud. 


\section{Background}

Although Ezafe has been studied by many scholars such as Mo'in (1962), Homayunfarrokh (1960), Palmer (1971), Samiian (1983), and Karimi and Brame (1986), the grammatical status of Ezafe has not yet been fully clarified. Grammarians have regarded Ezafe as a polysemous word carrying over ten different meanings/functions (Parsafar, 2010). Ezafe is generally regarded as a semantically vacuous phenomenon which may be iterated within the noun phrase and can be employed as many times as there are modifiers. For this reason, Lazard (1966) uses the term joncteur 'linker' to refer to Ezafe. Accordingly, Ghomeshi (1997) proposes viewing Ezafe as a 'linker' inserted within phonetic form to indicate phrasing, and not as a morpheme (or functional head). According to Samiian (1994), Ezafe is a case enclitic while Kahnemuipour (2000) and Larson and Yamakido (2005) adopt the opposite view and treat it as an enclitic associated with the syntactic movement of the noun and realizing a strong feature in the minimalist sense. The Ezafe is not limited to Persian; it can also be traced in some other languages with roughly similar functions. The Indo-Iranian language Zazaki exhibits the Ezafe construction in a significantly more complex form than Modern Persian. Whereas Ezafe is invariant (up to phonological alternation) in Persian, in Zazaki the Ezafe element inflects according to the number and the gender of the modified noun. Furthermore, Zazaki distinguishes between a descriptive Ezafe, which links a modified noun with an adjective, and a genitive Ezafe, which links a noun to another noun in the possessive relation. In addition, it appears that Japanese also makes a very similar distinction in its system of marking for prenominal modifiers. Japanese contains a morpheme '-no' that is used to link a noun with an NP/DP in a genitive or modifying relation (Larsen \& Yamakido, 2005).

\section{Methodology}

This paper aims to deal with a syntactic and / or phonological unit (i.e. Ezafe) in the Persian language. It is attempted to contrast the Persian invisible phoneme with its different realizations in English. It tries to define and classify the application of Ezafe and present some pedagogical implications.

\section{Classification of the Ezafe}

The Ezafe is an unstressed enclitic phoneme. According to Kalbassi (2005), a clitic is a type of morpheme which does not have an independent application, but like the affixes, it is attached to a word and unlike them, it is not part of the word. The clitic which is attached to the beginning of the root is called proclictic and the one which is suffixed to the word is an enclitic. However, Ezafe is not a morpheme because it has no physical visual realization; it fact, it is a phoneme. It is usually placed, or rather heard, after nouns, pronouns, adjectives and even some prepositions provided that there is a modifier following them. The Ezafe is verbally (not usually in writing) realized in two formats. The base form is an / -e / vowel which is added to a consonant-ended word; its allophone is / =ye / which is suffixed to the word that has a final vowel. However, in standard Persian orthography (based on the Arabic script), it is not indicated at all (except for careful writing or a stylish version). Thus in the written language, the presence of an Ezafe can usually be inferred only from the context and when the adjacent words are read aloud. In this article, the use of the Ezafe enclitic is dealt with in terms of the different categories.

\subsection{Noun + Noun}

According to Persian word order system, the modifier usually follows the modified nouns. That is, unlike English, the modifying noun follows the noun being described. When a noun precedes another noun, the first one receives the Ezafe (from here on, EZ) enclitic:

1. KETAAB -e SHIMI

book + EZ chemistry

a chemistry book

2. KAASE-ye QAZA

Bowl + EZ food

A food bowl

NOTE:

There are some cases which violate the rules of $\mathrm{N}+\mathbf{E Z}+\mathrm{N}$ :

1). In AAB PORTEQAL (water + orange, i.e. orange juice) and AAB LIMOO (water + lemon, i.e. lime juice), KETAAB FOROOSH (book + seller, i.e. book seller), KETAAB XAANEH (book + house, i.e. library), to mention a few, the Ezafe enclitic can be deleted because when these two words are put beside each other, there is 
now a new but related entity (in fact, a compound noun). So these are cases of lexicalizations (Lazard, 1992; Ghomeshi, 1996) and there is no need for an Ezafe enclitic.

In case of contrast, however, the Ezafe enclitic can be inserted between the two constituents to distinguish one item from the other. In the following example, the Ezafe enclitic has to be included to clarify which juice is meant:

A: What is this? Is this AAB PORTEQAL (i.e. orange juice)?

B: No, it is AAB-e LIMOO (water from lemon; lime juice).

2). Sometimes, there is no deletion, because the new entity does not have a high frequency.

AAB-e SIB (i.e. apple juice); AAB-e ANGOOR (i.e. grape juice); AAB-e ANAAR (i.e. pomegranate juice)

3 ). Sometimes, the presence or absence of Ezafe can lead to quite different entities. Consider the combination of ANBAAR (i.e. tank or store) and AAB (i.e. water) below:

3. AAB-e ANBAAR (i.e. water from the tank)

4. AAB ANBAAR (i.e. water tank)

In (3) the referent is water which is from a tank, while in (4) the referent is a tank which is used to store water in. In fact, the latter is a version of the ANBAAR-e AAB (i.e. tank for water) which has been reversed in order. Maybe this is a rare case in Persian or because of overuse, it has lost the Ezafe. There are many combinations in which ANBAAR (store or tank) is placed first: ANBAAR-e NAFT (i.e. oil tank), ANBAAR-e GHALEH (i.e. crop store or silo), ANBAAR-e KAH (i.e. straw barn) etc. Other similar examples include, BAADAAM ZAMINI (i.e. peanut) and BAADAAM-e DERAXTI (i.e. almond) irrespective of the second constituents of the word (ZAMINI, i.e. ground) and (DERAXTI, i.e. tree), the difference is just an Ezafe enclitic, but the referents are different. This can possibly go back to the high frequency and most price-accessibility of the former which leads to the dropping of the Ezafe enclitic. This is also true for SIB ZAMINI (i.e. potato) and SIB-e DERAXTI (i.e. apple) in which the former is mostly part of common staples than the latter is.

4). In the course of time, according to the principle of least effort propounded by George Zipf, saying that it is human nature to want the greatest outcome for the least amount of work (Sprague, Online), human tries to simplify things and express the most with the least energy and so the deletion of the Ezafe enclitic may be one case. Moreover, as Lazard (1992) points out, the Ezafe is frequently dropped in rapid colloquial speech when its omission does not make the utterance ambiguous or obscure.

In English, the nominal modifier can be expanded into different forms and the Ezafe plays a significant role in the respective counterpart structure in Persian:

a) "The door handle" can be paraphrased into "The handle to the door" which is a case of genitive structure. This is translated into DASTE-ye DAR (handle + EZ + door) where an Ezafe is inserted in place of the English preposition.

b) "A war story" is rewritten as "a story about war" while in Persian the word war is translated into an adjectival form; that is, JANGI (i.e. war-like) rather than the nominal form JANG (i.e. war). Again, an Ezafe is inserted: DAASTAAN-e JANGI (story + EZ + warlike).

c) "A glass door" can be expanded into "a door made of glass", but in Persian, it takes the form of an adjective SHISHEH (n. i.e. glass) vs SHISHEI (adj. made of glass or glass-like): DAR-e SHISHEI (door $+\mathbf{E Z}+$ glass like)

d) "A coat hanger" is equal to "a hanger for coats". In Persian, this is considered as a compound noun: CHOOB RAXTI (stick + clothes) or RAXT AAVIZ (i.e. clothes hanger) Here no Ezafe is added, because there is a case of lexicalization; that is, a compound noun has been formed.

e) "A shoe shop" is a shop where shoes are sold. In Persian, the English compound nouns dealing with shop words are usually translated into different phrases as in:

1). A shortened agentive noun; this is a noun which has the function of an adjective; it is in fact the English present participle. For example, a shoe shop is translated into: MAGHAAZE-ye KAFSHFOROOSHI" (i.e. a shoe-selling shop) for short, KAFSHFOROOSHI or a flower shop is translated into MAGHAAZE-ye GOLFOROOSHI (i.e. a flower-selling shop, for short GOLFOROOSHI.

2). When the shop compound is made after the profession, just a suffix (i.e. / $-\mathrm{i} /$ ) is added to the profession to refer to the shop: 
butcher (Persian: QASSAAB) => butcher's (Persian: QASSAABi $)$

baker (Persian: NAANVAA) $=>$ baker's (Persian: NAANVAAi)

f) "A milk bottle" is "a bottle for drinking milk from". In Persian it is BOTRI-ye SHIR (bottle + EZ + milk).Again an Ezafe is inserted.

g) "Bottle milk" is "milk contained in a bottle". Contrary to (f) above, the nominal modifier is translated into an adjective: SHIR-e BOTREI (milk + EZ + bottled) and since there is a noun followed by an adjective, an Ezafe is added.

h) "A chain watch" is "a watch that has a chain strap". In Persian, it is translated into a reduced relative clause: SAA'AT-e ZANJIRDAR (i.e. a watch with a chain; or a chain-bearing watch). Although "a chain store" has a similar structure to "a chain watch" and the meaning is apparently different, there is as much a close relation with the strap as the branches have with the main store. However, in spite of different equivalents in Persian, in both cases there is an Ezafe inserted after the noun: SAA'AT-e ZANJIRDAR (i.e. a watch with a chain) and FOROOSHGAH-e ZANJIREI (i.e. a store with chains). It seems Ezafe is an indispensable part in noun groups.

\subsection{Noun + Adjective}

Unlike English, Persian has a word order system in which adjectives usually follow the nouns. Adjectival modifiers can be grouped into three classes:

\subsubsection{Possessive}

When a noun is in the possession of another noun, the possessed noun needs the Ezafe enclitic:

5. KETAAB $\underline{-\mathbf{e}} \mathrm{ALI}$

book + EZ Ali

Ali's book

6. XANE $=$ ye ALI

house + EZ Ali

Ali's house

Related to this is the case of genitive case for non-living things where English resorts to the preposition "of", while Persian can just insert an Ezafe enclitic between the part and the whole word:

\section{LAMP-e OTAGH}

lamp $+\mathbf{E Z}$ room

The lamp of the room

8. DOGME - ye PIRAHAN

button $+\mathbf{E Z} \quad$ shirt

The button of the shirt

4.2.2 Positive adjectives

When a Persian noun is described by a positive (i.e. simple) adjective, the noun requires the Ezafe enclitic:

9. DAR-e ZARD

Door $+\mathbf{E Z}$ yellow

Yellow door

10. $\mathrm{BACHE}=$ ye ZIBA

Child + EZ pretty

Pretty child

It should be noted that an Ezafe enclitic may not be required for the combinations which are used emphatically or stylishly. In these cases, the adjectives are usually used as pre-modifiers. In (11) and (12) below, the adjectives NIK (i.e. nice) and ZIBA (i.e. beautiful) are used after and before nouns to give certain emphasis:
11. MARD-e Nik
man $+\mathbf{E Z}$ nice
vs NIK MARD
vs nice man 
$\begin{array}{llrr}\text { 12. ROOY-E ZIBA } & \text { vs } & \text { ZIBA } & \text { ROO } \\ \text { face beautiful } & \text { vs } & \text { beautiful face }\end{array}$

NOTE:

It sometimes happens that the presence or absence of Ezafe can convert an adjective phrase into a noun phrase. For example, the arrangement of BOZORG (i.e. big / great) and PEDAR (i.e. father) next to each other can lead to two interpretations. Firstly, when there is an Ezafe after the noun, it presents an adjective plus a noun: PEDAR (i.e. father) +EZ + BOZORG i.e. (big/ great/ important) a father who is great / big. There is a sense of respect saying that he is spiritually a big man although it may as well include high age. The following sentence can illustrate the point better:

\section{OO PEDAR-e BOZORG-e MAAST.}

He father $\mathbf{E Z}$ big $\quad$ EZ our is

He is our important/ great father.

Secondly, when there is no Ezafe, it makes a compound noun:

14. PEDAR BOZORG

father big/great

Grandfather

As another example, the word $\boldsymbol{A H A N I}$ (i.e. made of iron) can have two realizations based on the presence or absence of the Ezafe enclitic:

15. ADAM -e AHANI

Human $+\mathbf{E Z}$ iron

Strong man/human

While this phrase is used without an Ezafe, it can mean a "robot".

16. ADAM AHANI

human iron

Robot

4.2.3 Persian superlative adjectives

Persian superlative adjectives are usually pre-modifiers; that is, the adjective can precede the head provided that the head is singular. In this case, the adjective does not take the Ezafe enclitic:

\section{ON GERANTARIN}

MASHIN AST.

It most expensive

car

is

It is the most expensive car.

However, when the noun following the adjective is plural, the Ezafe is needed:

18. ON GERANTARIN-e

MASHINHA AST

it most expensive $+\mathbf{E Z}$

cars

is.

It is of the most expensive cars.

4.2.4 Adjectives + prepositions

In English, some adjectives that are followed by a noun require a preposition, for example:

She is afraid of dogs.

I was interested in the film.

In Persian, in some cases there are some equivalents for the prepositions and in some there is only an Ezafe. The adjective worried (in Persian NEGARAN) is a case in point in which there is an Ezafe enclitic in place of the preposition:

19. MAN NEGARAN-e DOOSTAM HASTAM.

I worried $+\mathbf{E Z}$ my friend am

I am worried about my friend. 
This usually happens in Persian when the adjective concerned is an agentive type or a participial adjective. It should be noted that in Persian the agentive adjectives and agentive nouns are almost always interchangeable; for example, GOOYANDEH (speaker) is a noun and it can be used as an adjective, too as in the MARD-e GOOYANDEH (i.e. man speaker; that is the speaking man although it can also refer to the gender, too.).

\subsection{Ezafe and Prepositions}

In Persian, there are some prepositions which can / cannot be followed by the Ezafe enclitic. There are three classes of prepositions (Samiian, 1994):

4.3.1 Preposition of location

Some prepositions referring to the location of a noun require an obligatory Ezafe enclitic: ZIR, POSHT, PAHLOO, JELO, DAAXEL, BIROON, BAALAA, PAAEEN, SAR, NAZDIK, MIAAN, and DOR (i.e. under, behind, next to, in front of, inside, outside, above, below, on, near, through, and around, respectively)
20. ZIR - e MIZ under $+\mathbf{E Z}$ table
Under the table
21. POSHT-e MIZ
behind $+\mathbf{E Z}$ table
Behind the table

\subsubsection{Optional prepositions}

Prepositions that can optionally (especially in informal speech) take the Ezafe include TOO, (i.e. inside) ROO (i.e. on):

22. TOO (-ye) OTAQ

in (EZ) room

Inside the room

23. ROO (-ye) MIZ

on + EZ table

On the table

\subsubsection{Preposition of location / time}

There are some prepositions of location / time that do not take the Ezafe enclitic. They include DAR, AZ, BE, TAA, BA'DAZ, and QABL'AZ, (i.e. in, from, to, until, after, and before, respectively) (http://farsi.tardid.net/tag/). For example:

a)

\section{DAR KELAS \\ in class \\ In class}

25. AZ BAZAAR

from market

From the market

26. BA'DAZ SHAAM

after dinner

After dinner

NOTE:

Prepositions BA'DAZ and BA'D both mean "after"; however, the former takes no Ezafe, while the latter does:

BA'D-e SHAAM

This is also true for QABL'AZ and QABL (i.e. before) 


\subsubsection{Preposition "BE"}

The preposition "BE" meaning "to" does not need an Ezafe. It can have two functions. Firstly, it can serve as a verb preposition which stands before an indirect object

\section{MAN $\underline{\boldsymbol{B} \boldsymbol{E}}$ OO GOFTAM.}

I $\underline{\text { to }}$ him said

I said to him.

Secondly, it can be used as a location preposition appearing before a place name:

\section{OO $\underline{\boldsymbol{B} E}$ MADRESSEH RAFT}

he to school went

He went to school.

However, when the preposition " $\boldsymbol{B} \boldsymbol{E}$ " is combined with a direction noun, the Ezafe enclitic is added to the noun.

29. OO BE TARAF-e XIAABAAN RAFT.

he to direction $+\underline{\mathbf{E Z}}$ street went

He went toward the street.

\subsection{Classifier}

In the case of the English partition or classifier where "of" is intermediary between the nouns on either side, Persian is not obligated to include anything to play the role of the English preposition. For example, "A spoonful of rice" and "Two bags of sugar" can be expressed as in (30) and (31) below:

30. YE GHASHOGH (eㅡ) BERENJ

a spoon $(+\underline{\mathbf{E Z}})$ rice

31. DO KISE (-ye) SHEGAR

two bag $\quad(+\underline{\mathbf{E Z}})$ sugar

However, if the classifier is qualified by a relative clause, the Ezafe is necessary:

32. ON GHASHOGH-e BERENJI KE XORDAM XOSHMAZE BOOD

that spoon $+\mathbf{E Z}$ rice that I ate delicious was

The spoonful of rice that I ate was delicious.

\subsection{Ezafe and Infinitives / Gerunds}

As Samvelian (Online) said the Ezafe construction is not restricted to head nouns. It can occur with mixed categories, such as infinitives, which may regularly head nominal projections in Persian. In this case, Ezafe introduces the 'subject' or the 'direct object' of the infinitive, but not both of them simultaneously.

When the infinitive is an intransitive one, it does not take an Ezafe:

\section{RAFTAN BE BAZAAR.}

To go to market

To go / Going to the market

But when an infinitive / gerundive construction is accompanied by an object, it is necessary to insert an Ezafe, because the infinitive/gerund serves as a noun followed by another noun:

\section{DIDAN -e FILM XOOB BOOD}

To see $+\mathbf{E Z}$ film good was

To see / Seeing the film was good.

If the noun precedes the infinitive / gerund, no Ezafe is needed because there is, in fact, a compound noun formed hereby and compounds do not usually require an Ezafe enclitic:

\section{FILM DIDADN XOOB BOOD}

film seeing good was

Film-watching was good. 
It should be noted that since the infinitive enclitic is the suffix /-AN/, Persian infinitives never end in a vowel. Accordingly, there is only one form of the Ezafe enclitic without any allophones.

\subsection{Ezafe and articles}

Ezafe can represent the definite article in Persian. It can realize as/ $\underline{-e}$ / or /-he/:

$$
\begin{array}{lrr}
\text { 36. } \text { KETAAB-e }^{\text {ROO-ye }} & \text { MIZ BOOD } \\
\text { book }+\underline{\mathbf{E Z}} \text { definite enclitic on }+ \text { EZ } & \text { table was }
\end{array}
$$

The book was on the table.

\section{BACHE-he RA DIDAM}

child $+\underline{\mathbf{E Z}}$ definite enclitic object marker I saw

I saw the child.

NOTE:

According to Samvelian (online), $\underline{\boldsymbol{e}}$ /-he is a highly cohering affix, since it bears lexical stress. At this point, it should be mentioned that in Persian, nouns and adjectives receive lexical stress on the last syllable. When a plural suffix or the definite $-\boldsymbol{e} / \boldsymbol{h} \boldsymbol{e}$ is added to a noun, the lexical stress moves one syllable to the right, on the suffix. Therefore, these affixes are like derivational suffixes and behave as though they were truly part of the word they adjoin. When a definite article is suffixed to a Persian adjective phrase, the Ezafe enclitic drops from the end of the noun and moves to the end of the adjective. Compare (38-a and b) and (39-a and b) below:

38. a)

XODKAAR-e AABI

pen $+\underline{\mathbf{E Z}}$ blue

A blue pen

38. b)

\section{XODKAAR AABI-ye}

INJA AST.

pen

blue $+\underline{\mathbf{E Z}}$ Definite here is

The blue pen is here.

39. a)

$\begin{array}{lc}\text { SAG-e SIA DAR } & \text { OTAQ AST } \\ \operatorname{dog}+\mathbf{E Z} \text { black in } & \text { room is }\end{array}$

There is $\underline{\mathbf{a}}$ / the black dog is the room.

39. b)

SAG SIA-ye DAR OTAQ AST

$\operatorname{dog}$ black $+\mathbf{E Z}$ in room is

The black dog is in the room.

In Persian the indefinite article is an / $-\mathrm{i} /$ which is usually added to the end of the noun:

40. $\mathrm{KETAAB}+\mathrm{i}$

book indef. Enclitic

A book

But when the noun is modified by an adjective, the indefinite enclitic is transposed to the end of the adjective and then the noun takes the Ezafe:

41. KETAAB-e XOOB $+\mathrm{i}$

book EZ good indef. Enclitic

A good book

However, it is possible to add the indefinite enclitic to the noun when sounding highly formal as in KETAAB $\underline{\boldsymbol{i}}$ XOOB (i.e. a good book) 
Nevertheless, when it comes to noun-noun modifier, there is only one choice: the head (that is, the noun) takes the Ezafe and the indefinite article is suffixed to the modifier:
42. KETAAB-e
GERAMERi
XARIDAM.
Book $+\mathbf{E Z}$
grammar + indef. Enclitic
I bought

I bought a grammar book.

\subsection{Ezafe and recursive structure}

Recursion refers to the property of allowing a given structure to contain more than one instance of a given category (Radford, 2004). In other words, two or several identical categories can follow each other. In Persian, even a recursive structure requires an Ezafe for all the preceding constituents. The following example shows recursion in nouns:

\section{KAGHAZ-e TAHRIR-e XATDAR-e SEFID \\ Paper $+\quad$ EZ writing + EZ ruled $+\mathbf{E Z}$ white}

The white ruled writing paper

When several adjectives are listed consecutively, there are two choices with respect to the application of the Ezafe enclitic:

The first one is that all the adjectives listed except for the last one can take the Ezafe enclitic:

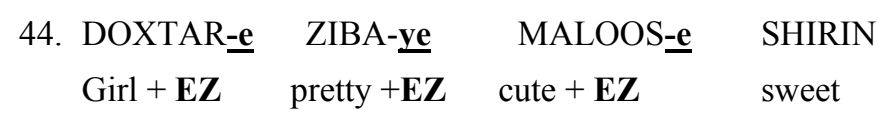

The cute sweet pretty girl

The second choice is to use the conjunction "and" in order to join the adjectives. This linking word is usually represented by Persian "O" or "VA" both of which mean "and". The former is used in informal contexts particularly in speech while the latter is used in formal texts. All the adjectives but the last one are suffixed by the linking vowel: "O" or "VA". The phrase "the cute sweet and pretty girl" is given in two versions (45) and (46) below:

45. informal contexts:

$\begin{array}{cllr}\text { DOXTAR-e } & \text { ZIBA- } & \text { MALOOS- } & \text { SHIRIN } \\ \text { Girl }+ \text { EZ } & \text { pretty + Linking vowel } & \text { cute + Linking vowel } & \text { sweet }\end{array}$

46. formal contexts:

$\begin{array}{lll}\text { DOXTAR-e } & \text { ZIBA, MALOOS } \underline{\text { VA }} & \text { SHIRIN } \\ \text { Girl }+ \text { EZ } & \text { pretty }+ \text { cute }+ \text { Linking word } & \text { sweet }\end{array}$

4.8 Ezafe and pronouns

Ezafe can also be added to the nouns which are followed by pronouns:

47. KETAAB-e ONHA

book + EZ they

Their book

If pronouns are followed by an adjective and there is a sense of emphasis, the Ezafe enclitic can be inserted:

48. MAN-e TANBAL

I + EZ lazy

I, the lazy

4.9 Other uses of Ezafe

1). The Ezafe enclitic can also be used in place of the Persian verb AST ("be") in informal contexts:

49. KHODA BOZORG-e

God great $\underline{\text { is }}$

God is great. 
2). When somebody introduces themselves, it very common to add an Ezafe enclitic to the end of each name but the last one. For example, "Saeed-e Ahmadi" rather than "Saeed Ahmadi". This can make confusion particularly with names whose genders are distinguished just by an Ezafe enclitic. For example, Saeed and Saeed-e(h) are referred to boys and girls, respectively. So in Persian a male speaker normally introduces himself as: My name is Saeed-e Ahmadi. If there is no help on the part of sound and face discrimination, there would be confusion as to whether the person is male or female. However, this does not occur with the names ending in /-e $/ \mathrm{or} / \underline{\mathbf{e}} / \mathrm{such}$ as Shokoofe or Taraneh.

3). Demonstrative adjectives and numerals do not take the Ezafe:

$$
\begin{aligned}
& \text { 50. IN XODKAAR } \\
& \text { this pen } \\
& \text { This pen } \\
& \text { 51. DO XODKAAR } \\
& \text { two pen } \\
& \text { Two pens }
\end{aligned}
$$

4). Some English verbs are used with a preposition, while their Persian equivalents are not. In this case, Persian uses the Ezafe to fill in the gap. For example, in the sentence "He reminds me of my friend." the substitute for "of" is an Ezafe in Persian:

$$
\begin{array}{rcrccc}
\text { 52. OO MAN } & \text { RA } & \text { BE } & \text { YAD } \underline{e} & \text { DOOSTAM } & \text { MIANDAZAD. } \\
\text { He me } & \text { Object Enclitic } & \text { to. } & \text { memory }+\mathbf{E Z} & \text { my friend } & \text { puts }
\end{array}
$$

Cases like this seem too minor to be taken care of by the learners but they may potentially cause problems when transferring ideas from Persian to English, because a beginner Iranian EFL learner usually tries to find equivalents for what he sees but not for what is invisible. The Ezafe marker easily skips the attention of the learner because he views it as the obvious requiring no specific attention. It is just like the Arabic phonetic diacritics commonly used in Persian but hardly ever written on paper.

5). Pre-modifying ordinal numbers do not take the Ezafe, but post modifying ordinal numbers need one:

$\begin{array}{lll}\text { 53. AVALIN GAAM vs } & \text { GAAM-e AVAL } \\ \text { first step } & \text { step }+ \text { EZ first } \\ \text { The first step } & \text { The first step }\end{array}$

Pre-modifying cardinal numbers which count the nouns do not take the Ezafe, but post modifying cardinal numbers which specify the type or order need an Ezafe.
54. DO KETAAB
vs
KETAABA-e DO
book $\quad$ EZ two
two book
The second book / Book two

\section{Conclusion}

Learning language requires that the learner be immersed in and exposed to language both explicitly and implicitly. In the explicit curriculum, language instruction is taught for limited and specified periods of time while the implicit curriculum provides students more exposure to the target language in an authentic and meaningful context, which is conducive to language learning (Genesee, 1994). What most Iranian learners seem to lack is the insufficient exposure to English through interactions. Correct reading and hence appropriate comprehension of a sentence can sometimes be based upon the type of the verb which appears at the end of a Persian sentence; that is to say, an Iranian speaker cannot be sure whether or not to insert an Ezafe unless he sees the verbs for transitivity. If the verb is intransitive, the first noun is taken as the subject, the noun following it will serve as a modifier and so the subject usually requires an Ezafe as in (55) below, but if the verb is transitive, the first noun will be the agent and the second noun will serve as the object of the verb and so no Ezafe will be inserted as in (56) below:

$$
\begin{aligned}
& \text { 55. MARD-e XARIDAAR AAMAD } \\
& \text { man EZ buyer came } \\
& \text { 56. MARD XARIDAAR AVARD }
\end{aligned}
$$


man buy brought

However, if the object is already known, an object marker namely, "RA" should be inserted immediately after the object. In this condition, the reader does not have to wait to reach the verb and then decide whether or not to insert an Ezafe, because the object marker lets him easily presume the final verb will be transitive and so the second noun after the agent is an object.

As a phoneme, rather than a morpheme, the Ezafe enclitic plays no semantic role, but syntactically and phonologically contributes to the fluency and comprehension of the message. It is mostly suffixed to a noun or noun substitute if there is another accompanying part of speech category. Ezafe follows the recursive rule and so it can occur as many times as possible as long as there are modifiers (i.e. post modifiers, in Persian). Ezafe does not bear lexical stress and in rapid delivery, especially in colloquial Persian, it is quite inaudible or even dropped. As an important feature in the Persian language, Ezafe occurs inside noun phrases, adjective phrases and some prepositional phrases. It can link the head to its modifiers or to its unique complement. Without the Ezafe enclitic, Persian speakers cannot handle language naturally and will sound like a mechanical robot speaking. For an Iranian EFL learner, it is a must to be aware of the English substitutes for the Persian Ezafe.

\section{References}

[Online] Available: http://farsi.tardid.net/tag/

Genesee, F. (1994). Integrating Language and Content: Lessons from Immersion. NCRCDSLL Educational Practice Reports, UC Berkeley.

Ghomeshi, G. (1997). Non-projecting Nouns and the Ezafe Construction in Persian. Natural Language and Linguistic Theory, 15-4:729-788.

Haig, G. (n.d.). Linker, relativizer, nominator, tense-particle: On the Ezafe in the west of Iran. [Online] Available: http://www.engl.polyu.edu.hk/research/nomz/files/HAI.Iranian.final.pdf (July14, 2011)

Homayunfarrokh, A. R. (1960). Dastur-e jame-ye zaeban-e Farsi. [A comprehensive grammar of the Persian language]. $2^{\text {nd }}$. ed. Tehran: Elmi Press.

Kahnemuyipour, A. (2000). Persian Ezafe Construction Revisited: Evidence for Modifier Phrase. Paper presented at Proceedings of the Canadian Linguistic Association Conference, Edmonton.

Kalbassi, I. (2005). Saaxt-e eshteghaaghi vazhe dar Farsi emrooz [Derivational morphology of modern Persian words]. Tehran: Cultural studies and research center of Iran (Pazhooheshgah).

Karimi, S. \& Brame, M. (1986). A Generalization Concerning the Ezafe Construction in Persian. Paper presented at The Annual Meeting of the Western Conference of Linguistics, Canada.

Larson, R. K. \& Yamakido, H. (2005). Ezafe and the Deep Position of Nominal Modifiers. Paper presented at Barcelona Workshop on Adjectives and Adverbs, Barcelona.

Mo'in, M. (1962). Ezafe. Tehran: Ebn-e Sina Publications.

Palmer, A. (1971). The Ezafe construction in modern standard Persian. Ann Arbor, Michigan: University of Michigan.

Parsafar, P. (2010). Syntax, Morphology, and Semantics of Ezafe. Iranian Studies, Vol. 43, No. 5, 637-666. http://dx.doi.org/10.1080/00210862.2010.518029

Pollet S. (n.d.). When morphology does better than Syntax: The Ezafe construction in Persian. [Online] Available: http://web.gc.cuny.edu/dept/lingu/doc/sambelian (March 14, 2011)

Radford, A. (2004). Minimalist syntax: Exploring the structure of English. Cambridge University Press.

Samiian, V. (1983). Structure of phrasal categories in Persian: an X-Bar analysis. Los Angeles: UCLA dissertation.

Samiian, V. (1994). The Ezafe construction: some implications for the theory of X-bar syntax. In Persian Studies in North America, ed. M. Marashi, Marlyland: Iranbooks. 17-41.

Sprague Benjamin. (n.d.). George Zipf: Human behavior and the principle of least effort [Online] Available: http://www.teachspatial.org/content/george-zipf-human-behavior-and-principle-least-effort (July 21, 2011) 